\title{
Compósitos de PVC Reforçados com Fibra de Vidro: Utilização de Técnicas de Processamento Convencionais da Indústria Brasileira
}

\author{
Murilo B. Feltran \\ Centro de Tecnologia \& Inovação Vinílicos, Braskem S/A \\ Francisco R. V. Diaz \\ Departamento de Engenharia Metalúrgica e de Materiais, EPUSP
}

\begin{abstract}
Resumo: Este artigo apresenta o estudo da incorporação de fibra de vidro curta em composto rígido de poli(cloreto de vinila) - PVC - por meio de técnicas de processamento convencionais da indústria brasileira. Foram avaliadas as influências de: a) tamanho de fibra de vidro (tipo E); b) dosagem de fibra de vidro; c) dosagem de dióxido de titânio $\left(\mathrm{TiO}_{2}\right)$; e d) a temperatura de processamento nas propriedades físicas e mecânicas e na adesão entre a matriz polimérica e a fibra de vidro (Microscopia Eletrônica de Varredura - MEV). O custo-benefício dos compósitos foi calculado por meio de Índices de Mérito para os modos de carregamento mecânico encontrados nos tubos pressurizados para água fria (Cilindro com Pressão Interna) e perfis rígidos utilizados em construção civil (Barra em Flexão), devido ao grande uso de PVC nestas aplicações. Entre os resultados obtidos, destaca-se o aumento de $45 \%$ no módulo de elasticidade para os compósitos com $20 \%$ de fibra de vidro moída que, para algumas aplicações, pode apresentar uma relação custo-benefício bastante favorável.
\end{abstract}

Palavras-chave: Compósitos, PVC, poli(cloreto de vinila), fibra de vidro, reforço mecânico, índice de mérito.

\section{Glass Fiber Reinforced PVC Composites: Use of Conventional Processing Techniques Currently Employed in the Brazilian Industry}

\begin{abstract}
This article presents the impact of the short glass fiber incorporation in rigid PVC compound through conventional processing techniques currently employed in the Brazilian industry. It were studied the influences of a) glass fiber geometry (E type); b) glass fiber content; c) titanium dioxide content; and d) processing temperature in the physical and mechanical properties. The adhesion conditions between polymeric matrix and glass fiber was analyzed by scanning electron microscopy (SEM). Cost-benefit relation of composites was evaluated using materials index technique for mechanical conditions found in pressurized water pipes (cylinder with internal pressure) and in building construction profiles (beam loaded in bending). The results attained suggested that, in some cases, the mechanical properties enhancement (such as the increase of $45 \%$ in the modulus of elasticity for composites containing $20 \%$ of glass fiber) and the processing techniques required to produce it can present an interesting cost-benefit relation.
\end{abstract}

Keywords: Composites, PVC, poly (vinyl chloride), fiber glass, mechanical reinforcement, material index.

\section{Introdução}

A resistência a diversos agentes químicos, incluindo cal, cimento e produtos de limpeza comumente utilizados no dia-a-dia doméstico, resistência à corrosão e à ação das intempéries, facilidade de pintura e colagem, comportamento auto-extingüível em situações de incêndio e boa resistência mecânica aliada a uma excelente estabilidade dimensional tornam os produtos de PVC excelentes opções para os mercados de construção civil. Em síntese, os produtos de PVC apresentam excelente relação custo/benefício, pois aliam excelente desempenho a elevada durabilidade.

Outras propriedades comuns aos termoplásticos também são grandes vantagens quando consideradas no pro- jeto de um produto destinado à construção civil: reduzida massa específica, possibilidade de moldagem em qualquer desenho e/ou formato, contribuição ao isolamento térmico e acústico e facilidade de instalação, pois pode ser cortado, pregado e parafusado de modo mais fácil que os materiais convencionais da construção civil. Esta é a razão pela qual $63 \%$ da resina de PVC consumida no Brasil é destinada às aplicações ligadas à construção civil, na forma de produtos tais como: tubos, conexões, perfis para construção civil e fios e cabos ${ }^{[1]}$.

Diferentemente dos outros termoplásticos, o PVC é sempre processado com aditivos. A mistura da resina de PVC é normalmente realizada em misturadores intensivos,

Autor para correspondência: Murilo B. Feltran, Braskem S/A, Centro de Tecnologia \& Inovação Vinílicos, Avenida das Nações Unidas 4777 - $1^{\circ}$ andar CEP: 05477-000, São Paulo, SP, Brasil. E-mail: murilo.feltran@braskem.com.br 
os quais proporcionam excelente qualidade e homogeneidade da mistura, ciclos de mistura normalmente curtos, com tempos de mistura típico de um composto de PVC rígido entre 7 a 8 minutos, aumento da densidade aparente da mistura em relação aos componentes isolados e possibilidade de eliminação completa da umidade do composto. O ciclo de mistura recomendado para compostos de PVC rígido compreende a adição de todos os componentes da formulação no início e homogeneização em alta velocidade até que a temperatura da massa atinja entre 120 e $130^{\circ} \mathrm{C}$, condição esta necessária para que determinados componentes da formulação tais como, estabilizantes térmicos e lubrificantes sólidos, sofram fusão, sendo absorvidos ou revestindo por completo as partículas de resina ${ }^{[2,3]}$

Das 767 mil toneladas de resina de PVC consumidas no Brasil em 2006, aproximadamente 55\% ou 422 mil toneladas foram utilizadas em compostos de PVC rígido processados por extrusão ${ }^{[1]}$. A indústria de PVC rígido geralmente utiliza extrusoras de rosca dupla contra-rotacionais interpenetrantes, as quais possuem transporte de material mais eficiente, melhor mistura e maior troca de calor, podendo converter compostos em pó em um fundido homogêneo em menores temperaturas, o que proporciona uma margem de segurança contra degradação. O fluxo mais viscoso e a vazão mais homogênea possibilitam à extrusora de rosca dupla contrarotacional manter controle dimensional ao processo de extrusão de tubos e perfis de PVC rígido, além de necessitar de menores quantidades de estabilizantes térmicos e lubrificantes na formulação. Tudo isto resulta em uma redução de custo variável para o produto moldado através das extrusoras de rosca dupla contra-rotacional ${ }^{[4,5]}$.

Nos trabalhos publicados sobre compósitos de PVC rígido, a preparação dos compósitos geralmente é feita de em 2 estágios: o composto de PVC rígido é preparado separadamente em misturador intensivo, sendo o composto e a fibra de vidro homogeneizados em calandra de modo a impor baixos cisalhamentos à fibra de vidro, minimizando a quebra da fibra de vidro $^{[6-8]}$. O método é interessante para fins investigativos, mas muito distante de uma técnica aplicável à indústria.

O método de incorporação da fibra de vidro mais adequado é a mesmo utilizado para os demais compósitos termoplásticos reforçados com fibra de vidro: uso de extrusoras de rosca dupla co-rotacionais com alimentação lateral próxima do final da rosca, ou seja, geralmente após a degasagem. O composto de PVC rígido normal é preparado em misturador intensivo e a incorporação da fibra de vidro é realizada de forma eficiente, proporcionando boa mistura e baixo cisalhamento, devido ao desenho específico da rosca para o processamento de PVC rígido. Esta forma de incorporação é a utilizada pela PolyOne Corporation para a preparação dos compósitos Fiberloc ${ }^{\circledR}$, também sendo estudada por Balow e Fuccella $^{[9]}$ e por Summers e seus colaboradores ${ }^{[10]}$. A PolyOne Corporation é a principal empresa produtora de compósitos de PVC rígido com fibra de vidro. Ela incorpora 10 a $30 \%$ de fibra em massa para usos interno e externo, sob a marca Fiberloc $^{\circledR[11]}$.

Com o uso de técnicas e equipamentos convencionais da indústria, o conhecimento gerado neste trabalho pode ser transferido facilmente à cadeia produtiva do PVC. A proposta da pesquisa relatada neste é permitir a incorporação da fibra de vidro no processo tradicional de mistura e a extrusão dos compósitos de PVC rígido com fibra de vidro diretamente do pó em extrusoras de rosca dupla contra-rotacionais. O aumento da rigidez pela adição de fibras reforçantes pode ampliar o mercado dos produtos de PVC, seja pelo aumento das aplicações possíveis, devido à melhoria de desempenho, tais como de produtos como tubos para adução de água com pressões de serviço maiores, cujo limite definido pela norma NBR 7665 é de 1,6 MPa, ou pelo aumento da competitividade do produto nas aplicações atuais, tal como a redução da espessura de parede de perfis de janela ou perfis de decks, promovendo menor uso de material, menor custo e melhoria da posição competitiva destes produtos. Logicamente, a redução de espessura proporcionada pelo aumento da rigidez deve compensar os aumentos do custo da formulação, da massa específica do compósito e do custo de processamento esperados pela adição de fibra de vidro.

Diante dos requisitos de propriedades mecânicas que um determinado produto deve atender, podemos calcular o custo-benefício a partir dos conceitos de "Índice de Mérito", comumente utilizados nos estudos de seleção de materiais e bastante trabalhados por Ashby ${ }^{[12,13]}$ e Ferrante ${ }^{[14]}$. Como exemplo, podemos citar a razão entre módulo elástico e massa específica, que é utilizada para a minimização de massa para o modo de carregamento cilindro com pressão interna, condição mecânica similar à encontrada nos tubos pressurizados para água fria. Um aprofundamento deste índice pode ser dado envolvendo o custo do material: a razão entre o módulo elástico, a massa específica e o custo pode ser um guia eficaz para definir qual é a melhor opção de material para um dado produto de requisito mecânico definido. Logicamente, o cálculo pode ser mais complexo: este exemplo coloca apenas o custo do material e não considera as limitações que cada material tem de secções transversais, espessuras e custo de fabricação ${ }^{[13-15]}$.

\section{Experimental}

O experimento consistiu na avaliação da influência das seguintes variáveis:

S 4AMANHOMEDIODAl BRADE VDRO

- Nível 1: Fibra de vidro 737B picada: tamanho médio de $6,4 \mathrm{~mm}$.

- Nível 2: Fibra de vidro 737B moída: tamanho médio de $1,5 \mathrm{~mm}$.

S \$ OSAGEM DEl BRADE VDRO

- Nível 1: 5\% em massa.

- Nível 2: $20 \%$ em massa.

S \$ OSAGEMDED XIDODETIPNO 
- Nível 1: 0pcr (compostos para uso interno de cores não-claras).

- Nível 2: 8pcr (compostos para uso externo de cores claras).

\section{S 4EMPERATLRAS DEPROCESSAMENIO}

- Nível 1: Perfil de temperaturas nas zonas da extrusora de $170-175-180{ }^{\circ} \mathrm{C}$.

- Nível 2: Perfil de temperaturas nas zonas da extrusora de $190-195-200{ }^{\circ} \mathrm{C}$.

A fibra de vidro utilizada foi o tipo 737B de $14 \mu \mathrm{m}$ de diâmetro, gentilmente cedida pela Owens Corning. A fibra de vidro foi utilizada em 2 formas distintas: a picada (de comprimento médio $6,4 \mathrm{~mm}$ ) e a moída (de comprimento médio $1,5 \mathrm{~mm}$, resultante da moagem das fibras picadas) Como não há disponível no mercado brasileiro fibra de vidro com tratamento superficial específico para PVC, foi selecionado o tipo utilizado em compostos de poliuretano. Dado que PVC e PU possuem elevada afinidade química, os respectivos agentes de acoplagem seriam similares.

A formulação considerada Padrão é apresentada na Tabela 1 e foi baseada nas práticas comuns dos transformadores de perfis de rígidos de PVC do mercado brasileiro, também descritas por Rodolfo Jr et al. ${ }^{[3]}$.

A mistura foi realizada de forma convencional em misturador intensivo de laboratório Mecanoplast modelo ML-9, à exceção da fibra de vidro, a qual foi adicionada apenas no resfriador, de modo a promover a homogeneização durante o processo de resfriamento.

Depois de misturados, os compostos foram granulados na extrusora de laboratório Miotto (extrusora monorrosca $25 \mathrm{~mm}, \mathrm{~L} / \mathrm{D}=20 / 1$, taxa de compressão 3:1) com os perfis de temperatura $170-175-180{ }^{\circ} \mathrm{C}$ ou $190-195-200{ }^{\circ} \mathrm{C}$ e $50 \mathrm{rpm}$ de rotação de rosca. A preparação de corpos-de-prova a partir dos grânulos foi realizada por meio da plastificação das formulações em uma calandra de dois rolos Mecanoplast, à temperatura de $190{ }^{\circ} \mathrm{C}$ e com velocidade dos rolos igual a $20 \mathrm{~min}^{-1}$. As formulações permaneceram sob cisalhamento na calandra por 3 minutos, contados após iniciada a plastificação do PVC.

Do material plastificado em calandra, foram obtidas placas de $20 \mathrm{~cm} \times 20 \mathrm{~cm} \times 4 \mathrm{~mm}$ por prensagem em um gabarito de aço inoxidável na prensa Luxor à temperatura de $175^{\circ} \mathrm{C}$ durante 3 min à pressão de $100 \mathrm{Kgf} / \mathrm{cm}^{2}$, seguido de $0,5 \mathrm{~min}$ à pressão de $200 \mathrm{kgf} / \mathrm{cm}^{2}$ de modo a deixar as amostras totalmente planas. Após a prensagem, as placas foram resfriadas até a temperatura de $35^{\circ} \mathrm{C}$ sem abertura do gabarito na prensa.
Após esta etapa, as placas foram usinadas em equipamento de corte de jato de água de ultra alta pressão no Laboratório da Engenharia de Minas e Petróleo da Escola Politécnica (USP) de modo a obter corpos-de-prova para o ensaio de tração (conforme norma ASTM D-638:2003, tipo I) e para o ensaio de resistência ao impacto Charpy entalhado (conforme norma ASTM D-6110:2004). Foram confeccionados 10 corpos-de-prova para cada ensaio descrito, sendo condicionados por $40 \mathrm{~h}$ na temperatura de $(23 \pm 2)^{\circ} \mathrm{C}$ e $(50 \pm 5) \%$ de umidade relativa do ar, conforme as recomendações do procedimento ASTM D-618:2000.

Para a avaliação dos compósitos conforme os conceitos de Índice de Mérito, os custos de cada componente da formulação foram coletados (base junho/2007, custos com impostos). Devido ao pedido dos fornecedores dos aditivos em não publicar estas informações, o custo de matéria-prima de cada compósito foi calculado e será mostrado de forma totalizada. A Tabela 2 detalha os compósitos utilizados no experimento e respectivos custos de matéria-prima calculados.

Observação: O custo da fibra moída é cerca de $35 \%$ maior que o custo da fibra picada, devido à adição do custo de moagem da fibra.

O custo de transformação do composto considerado Padrão foi de $\mathrm{R} \$ 1,00 / \mathrm{kg}$. Este custo é aproximadamente o custo de processamento típico de perfis rígidos proveniente da experiência industrial prévia do autor no mercado de transformação de PVC, englobando o custo de mão-de-obra, gastos com energia elétrica dos equipamentos de processo e iluminação fabril, depreciação de equipamento entre outras despesas administrativas e operacionais.

Foram realizados os seguintes ensaios:

S OROPREDADES DO COMPOSTO \$ ENSIDADE APAFNE OU bulk density: conforme norma ASTM D-1895:1996;

s ! VALA1/áODOPROCESAMENIOPOREXIRLáO - ED1/2̂ODA produtividade mássica em $\mathrm{kg} / \mathrm{h}$;

S OROPREDADES FSICAS - ASSAESPBCप CA CONORME NOR ma ASTM D-792:2000;

s OROPREDADES MEC NCAS - DUO DE ELASTICIDADE SOB tração: conforme norma ASTM D-638:2003, em máquina universal de ensaios MTS, modelo Alliance 5/RT. Resistência ao impacto Charpy com entalhe: conforme norma ASTM D-6110:2005, equipamento de Impacto Ceast Resil 5.5;

s - ICROSCOPIA EIEIR NCA DE VARADURA 2 EAIZADA EM corpos-de-prova fraturados criogenicamente (de modo a evitar interferências de deformações plásticas na avaliação), em equipamento Philips XL30 EDAX do De-

Tabela 1. Formulação do composto padrão utilizada no experimento. As quantidades se encontram em pcr (partes por cem partes de resina de PVC).

\begin{tabular}{lcll}
\hline \multicolumn{1}{c}{ Componente } & Dosagem (pcr) & \multicolumn{1}{c}{ Fornecedor } & \multicolumn{1}{c}{ Função na formulação } \\
\hline Norvic $^{\circledR}$ SP 800 & 100 & Braskem S/A & Resina de PVC de valor K 61 \\
Naftosafe $^{\circledR}$ CZ-4004 & 4,0 & Chemson Ltda. & Complexo estabilizante à base de cálcio/zinco \\
Paraloid $^{\circledR}$ KM-334 & 8,0 & Rohm\&Haas Company & Modificador de impacto de base acrílica \\
Paraloid $^{\circledR}$ K-120ND & 1,0 & Rohm\&Haas Company & Auxiliar de processamento de base acrílica \\
\hline
\end{tabular}


Tabela 2. Compósitos utilizados no estudo e respectivos custo das matérias-primas (MP).

\begin{tabular}{lcccccc}
\hline Amostra & $\begin{array}{c}\text { Tipo de } \\
\text { fibra }\end{array}$ & $\begin{array}{c}\text { Dosagem de } \\
\text { fibra }(\boldsymbol{\%})\end{array}$ & $\begin{array}{c}\text { Dosagem de TiO } \\
(\mathbf{p c r})\end{array}$ & $\begin{array}{c}\text { Temperaturas de } \\
\text { extrusão }\left({ }^{\circ} \mathbf{C}\right)\end{array}$ & $\begin{array}{c}\text { Custo MP } \\
(\mathbf{R} \mathbf{\text { kg }})\end{array}$ & Custo MP $(\%)$ \\
\hline Padrão & - & 0 & 0 & $170-175-180$ & 4,32 & 100,0 \\
5PSA & Picada & 5 & 0 & $170-175-180$ & 4,45 & 103,1 \\
5PSC & Picada & 5 & 0 & $190-195-200$ & 4,45 & 103,1 \\
5PTA & Picada & 5 & 8 & $170-175-180$ & 4,75 & 109,9 \\
5PTC & Picada & 5 & 8 & $190-195-200$ & 4,75 & 109,9 \\
5MSA & Moída & 5 & 0 & $170-175-180$ & 4,58 & 106,0 \\
5MSC & Moída & 5 & 0 & $190-195-200$ & 4,58 & 106,0 \\
5MTA & Moída & 5 & 8 & $170-175-180$ & 4,87 & 112,8 \\
5MTC & Moída & 5 & 8 & $190-195-200$ & 4,87 & 112,8 \\
20PSA & Picada & 20 & 0 & $170-175-180$ & 4,85 & 112,4 \\
20PSC & Picada & 20 & 0 & $190-195-200$ & 4,85 & 112,4 \\
20PTA & Picada & 20 & 8 & $170-175-180$ & 5,10 & 118,2 \\
20PTC & Picada & 20 & 8 & $190-195-200$ & 5,10 & 118,2 \\
20MSA & Moída & 20 & 0 & $170-175-180$ & 5,35 & 124,0 \\
20MSC & Moída & 20 & 0 & $190-195-200$ & 5,35 & 124,0 \\
20MTA & Moída & 20 & 8 & $170-175-180$ & 5,60 & 129,7 \\
20MTC & Moída & 20 & 8 & $190-195-200$ & 5,60 & 129,7 \\
\hline
\end{tabular}

partamento de Engenharia Metalúrgica e de Materiais da Universidade de São Paulo (USP); e

s ! NÕISE SEGUND \&NDIE DE MÆRTO \&ORAM CACUADOS

os índices de mérito módulo elástico/massa específica e módulo elástico/massa específica/custo, considerando-se os carregamentos nos modos cilindro com pressão interna (condição mecânica similar à encontrada nos tubos pressurizados para água fria - E/ $\rho$ ) e barra em flexão (condição mecânica similar à encontrada nos perfis utilizados na construção civil, como forros de PVC - $\left.E^{1 / 2} / \rho\right)$.

$\mathrm{O}$ custo de transformação de cada compósito foi calculado de acordo com a Equação 1 e o custo total, conforme a Equação 2:

Custo de Transformação ${ }_{\text {Comp }}=$

$\frac{\text { Custo de Transformação }}{\text { Padrão }}$ produtividade $_{\text {Padrão }} \times$ produtividade $_{\text {Comp }}$

Custo total $_{\text {Comp }}=$

Custo das matérias-primas ${ }_{\text {Comp }}+$ Custo de transformação ${ }_{\text {Comp }}$

\section{Resultados e Discussão}

Os compósitos com $20 \%$ de fibra picada formaram aglomerados durante a incorporação de fibra de vidro realizada no resfriador, inviabilizando as análises destes compósitos. Deste modo, não serão apresentados resultados dos compósitos 20PSA, 20PSC, 20PTA e 20PTC.

\section{Densidade aparente}

Observa-se que o fator que mais influencia a densidade aparente (Figura 1) é a adição de dióxido de titânio: tanto no caso dos compósitos com 5\% de fibra picada e de $5 \%$ de fibra moída, a adição de 8pcr de dióxido de titânio eleva cerca de $8 \%$ a densidade aparente. Já adição de $5 \%$ de fibras picadas eleva $2 \%$ a densidade aparente em relação ao composto padrão. Por outro lado, a adição de fibras de vidro moídas praticamente não altera a densidade aparente: os compósitos com 5 e $20 \%$ apresentam a mesma densidade aparente do composto padrão. Estes efeitos podem ser explicados pela massa específica e formato dos aditivos em questão: a) o dióxido de titânio, de massa específica $4,1 \mathrm{~g} / \mathrm{cm}^{3}$ e tamanho de partícula variando entre 0,2 e $0,3 \mu \mathrm{m}$, preenche de forma mais eficiente os vazios existentes entre as partículas de PVC do que a fibra de vidro, de massa específica $2,54 / \mathrm{cm}^{3}$; e b) formato menos regular (pois é uma fibra), diâmetro da fibra $14 \mu \mathrm{m}$ e tamanho de fibra de $6,4 \mathrm{~mm}$ no caso das fibras picadas e 1,5 mm no caso das fibras moídas.

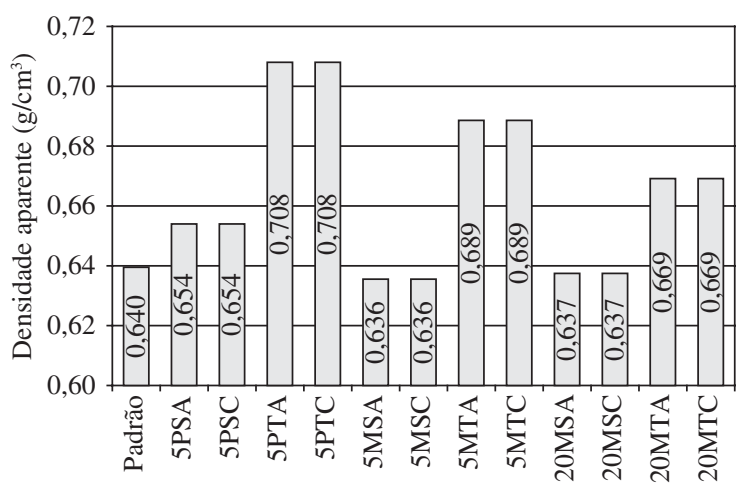

Figura 1. Densidades Aparentes (bulk density - BD) dos compostos preparados. 


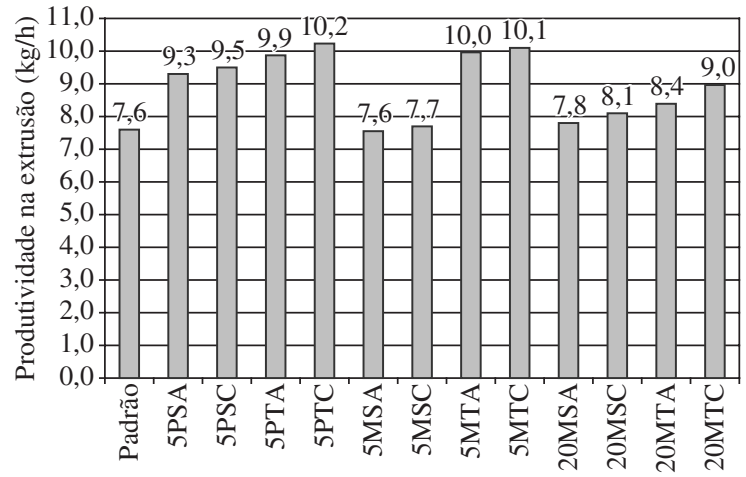

Figura 2. Produtividades apresentadas pelos compósitos durante a extrusão.

\section{Produtividade na extrusão}

Sabe-se que a densidade aparente influencia diretamente o rendimento do processamento por extrusão para compostos de PVC rígido. Se dividirmos os valores de produtividade (Figura 2) pela densidade aparente, verificaremos que em todos os casos obteremos índices entre 11,9 e 14,7, o que é um retrato desta relação direta. O coeficiente de correlação entre estas duas variáveis é de 0,88: pode-se verificar que esta relação é significativa e assumir que as variáveis que influenciaram a densidade aparente são as mesmas que influenciam a produtividade na extrusão.

\section{Massa específica}

Observa-se que mais influencia a massa específica (Figura 3) é a adição de 8,0 pcr de dióxido de titânio: o aumento da massa específica varia de $4,0 \%$ (no caso dos compósitos com 5\% de fibra picada ou moída) a 4,5\% (no caso dos compósitos com $20 \%$ de fibra de vidro moída), o que seria esperado devido a massa específica elevada do dióxido de titânio $\left(4,1 \mathrm{~g} / \mathrm{cm}^{3}\right)$. As variáveis, definidas como tamanho da fibra de vidro e temperatura de extrusão, não influenciam de forma significativa a massa específica. Já a dosagem de fibra de vidro influencia de forma menos acentuada a massa específica: a adição de 5\% de fibra de vidro moída eleva a massa específica em $2 \%$ e a adição de $20 \%$, em $8 \%$. Este efeito menos acentuado pode ser explicado pela massa específica da fibra

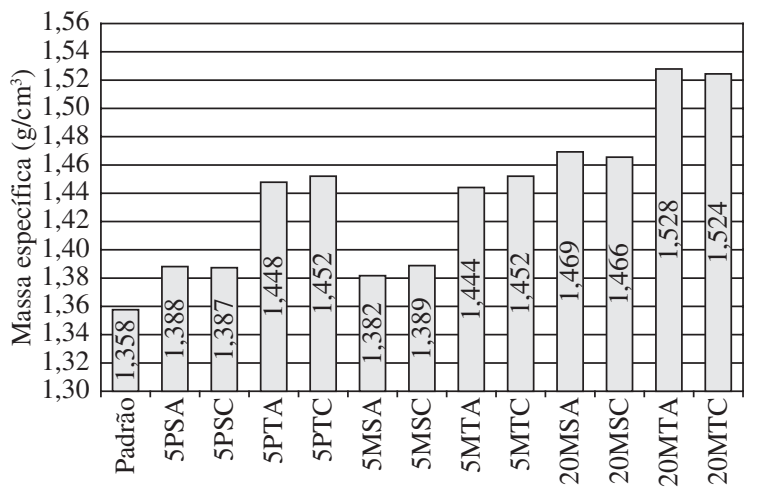

Figura 3. Massas específicas dos compósitos preparados. de vidro $\left(2,54 \mathrm{~g} / \mathrm{cm}^{3}\right)$ ser razoavelmente menor que a do dióxido de titânio.

Comparando-se os resultados obtidos nas amostras 20MSA e 20MSC com a especificação do compósito da Polyone Fiberloc ${ }^{\circledR} 80520^{[13]}$ (compósito de PVC rígido com $20 \%$ de fibra de vidro para uso interno) pode-se verificar que não existe diferença significativa $(\leq 0,3 \%)$. Na comparação os resultados dos compósitos 20MTA e 20MTC com a especificação do compósito da Polyone Fiberloc ${ }^{\circledR} 85520^{[13]}$, ou seja, compósito de PVC rígido com $20 \%$ de fibra de vidro para uso externo, com dosagem de titânio adequada para proteção à radiação UV, ou seja, entre 6 pcr e 12 pcr, pode-se verificar também diferenças insignificantes $(\leq 0,5 \%)$.

\section{Módulo de elasticidade sob tração}

Nota-se que a dosagem de fibra de vidro exerce influência significativa no aumento da propriedade (Figura 4), elevando a propriedade do patamar situado entre 2,3 e 2,6 GPa nos compósitos com $5 \%$ de fibra de vidro para o patamar situado entre 3,0 e 3,4 GPa nos compósitos com 20\% de fibra de vidro, o que representou um aumento médio de $30 \%$. Já o aumento entre os compósitos com 5\% de fibra de vidro e o composto padrão foi muito pequeno (de 2,2GPa para o patamar situado entre 2,3 e 2,6 GPa), enquanto que entre os compósitos com $20 \%$ de fibra de vidro e o composto padrão, o aumento médio foi de 45\% (de 2,2 GPa para o patamar situado entre 3,0 e 3,4 GPa). Aparentemente, as variáveis, tais como, temperatura de processamento, dosagem de dióxido de titânio e tipo de fibra de vidro exerceram influência pouco significativa.

Comparando-se estes resultados dos compósitos 20MSA e 20MSC com os obtidos por SILVERMAN ${ }^{[8]}$, no qual a resistência à tração para compósitos com $20 \%$ de fibra de vidro foi de $90 \mathrm{MPa}$ e módulo de elasticidade sob tração de $7,2 \mathrm{G} \mathrm{Pa}$, verificaremos que a resistência à tração e o módulo de elasticidade obtidos no presente estudo foram 55 a $60 \%$ menores. Esta diferença significativa pode ser atribuída a 2 fatores principais:

s OROCHDIMENIO DE PAPPARO DAS AMOSTRAS ENQUANIO OS autores citados recorreram à incorporação em rolos

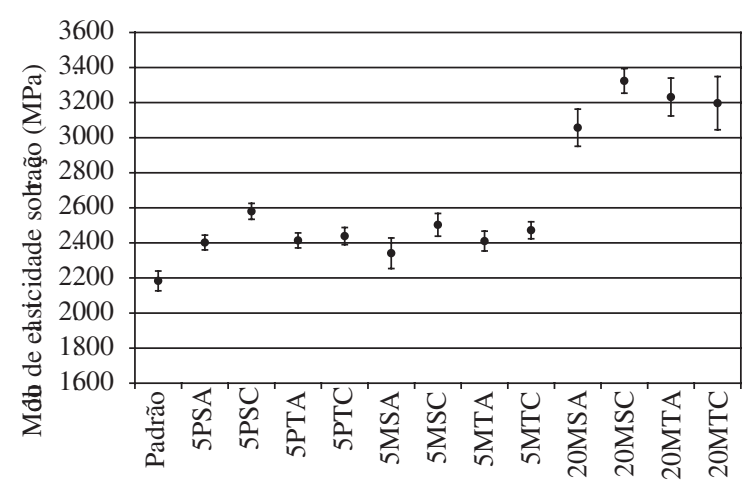

Figura 4. Módulos elásticos sob tração dos compósitos preparados. 
de calandra disponíveis em laboratórios (e não utilizadas para esta finalidade na indústria), o que impôs um cisalhamento muito baixo ao composto, o estudo em questão utilizou técnicas convencionais da indústria (incorporação em misturador intensivo e homogeneização em extrusora), as quais promoveram maior cisalhamento e, provavelmente maior quebra da fibra de vidro;

s ! I BRAUIIIZZADANESECASOFO Al BRAMOAADE MM de comprimento, diferentemente da utilizada nos estudos citados (fibra picada de 6,4 mm; compósitos com $20 \%$ deste tipo de fibra não puderam ser preparados utilizando as técnicas convencionais de mistura). $\mathrm{O}$ tratamento da fibra de vidro utilizada neste estudo também pode ser um ponto desfavorável: o autor americano utilizou fibras de vidro tratadas com agentes de acoplagem específicos para PVC, indisponíveis no mercado brasileiro.

Na comparação dos compósitos 20MSA e 20MSC com a especificação do compósito da Polyone Fiberloc ${ }^{\circledR} 80520$ (resistência à tração 79,3 GPa e módulo de elasticidade de $6,2 \mathrm{GPa})^{[13]}$ e dos compósitos 20MTA e 20MTC com a especificação do compósito da Polyone Fiberloc ${ }^{\circledR} 85520$ (resistência à tração 68,9GPa e módulo de elasticidade de 6,9 GPa) ${ }^{[13]}$, os mesmos resultados se repetem: a resistência à tração e o módulo de elasticidade obtidos no estudo foram 50 a $60 \%$ menores. Podemos atribuir esta diferença a 2 fatores similares:

s OROCHDIMENIO DE PAPARO DAS AMOSTRAS A OOYONE utiliza para a obtenção dos compósitos extrusoras de rosca dupla co-rotacionais com alimentação da fibra de vidro lateral próximo do final da rosca (geralmente na zona de degasagem), o que reduz sensivelmente o cisalhamento e a quebra da fibra de vidro em relação à técnica utilizada neste estudo; e

s 4IPODE1 BRAUIILZADANOEXPERMENIOE RATAMENIOSU perficial desfavorável: idem à análise anterior.

\section{Resistência ao impacto Charpy com entalhe}

A resistência ao impacto Charpy com entalhe (Figura 5) foi fortemente afeta pela dosagem de fibra de vidro, seja picada ou moída. Os valores médios de resistência ao impacto Charpy com entalhe caíram de $230 \mathrm{~J} / \mathrm{m}$ para valores médios entre 60 e $80 \mathrm{~J} / \mathrm{m}$ para os compósitos com adição de $5 \%$ de fibra de vidro e para valores médios entre 40 e $60 \mathrm{~J} / \mathrm{m}$ para os compósitos com adição de $20 \%$ de fibra de vidro. As variáveis, tais como, tamanho de fibra de vidro, dosagem de dióxido de titânio e temperatura de processamento exerceram influência pouco significativa na propriedade. Esta queda significativa na propriedade se deve ao efeito concentrador de tensões que a fibra de vidro exerce na matriz polimérica. Este efeito é um indício da pouca adesão entre fibra de vidro e matriz ocorrida nos compósitos.

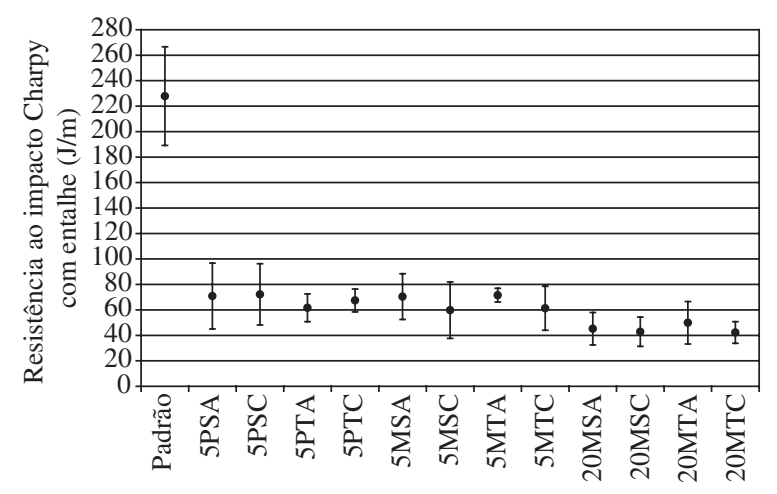

Figura 5. Resistência ao impacto Charpy com entalhe dos compósitos preparados.

\section{Microscopia eletrônica de varredura (MEV)}

Todas as imagens obtidas por meio da microscopia eletrônica de varredura (Figuras 6 a 8) mostraram a ocorrência do fenômeno de "pull-out" (fibras descoladas da matriz). Este efeito pode ser observado tanto nos compósitos de PVC com $5 \%$ de fibra de vidro quanto nos compósitos de PVC com $20 \%$ de fibra de vidro. Identificam-se vários vazios nos quais a fibra foi arrancada, o que evidencia a significativa quebra da fibra de vidro. É possível também verificar que as superfícies das fibras de vidro arrancadas apresentam-se bastante lisas, o que demonstra que a adesão entre fibra de vidro e matriz polimérica foi bastante baixa. As Figuras 6, 7 e 8 mostram micrografias eletrônicas de varredura selecionadas.
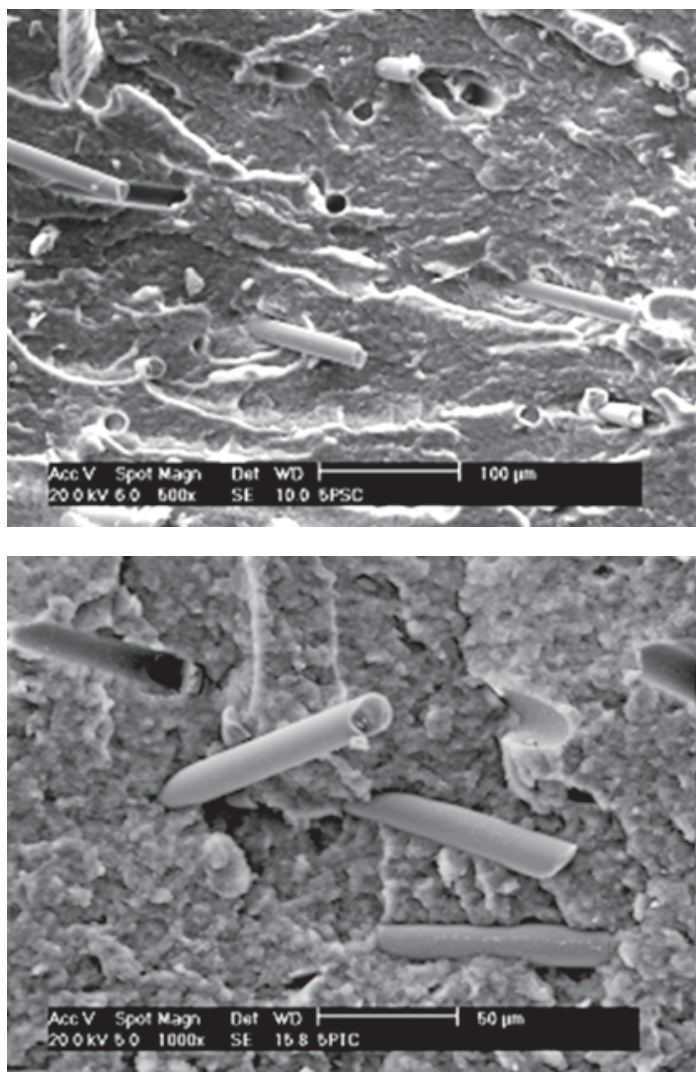

Figura 6. Micrografias eletrônicas de varredura dos compósitos com 5\% de fibra picada 5PSC (em aumento de 500x) e 5PTC (em aumento de 1.000x). 

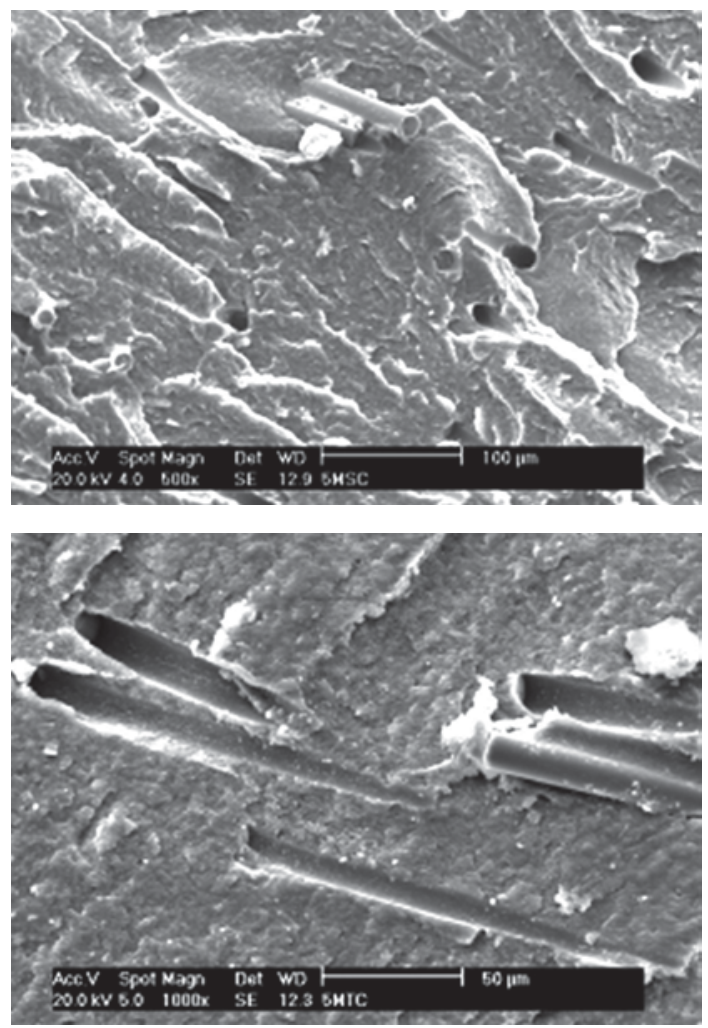

Figura 7. Micrografias eletrônicas de varredura dos compósitos com 5\% de fibra moída 5MSC (em aumento de 500x) e 5MTC (em aumento de 1000x).
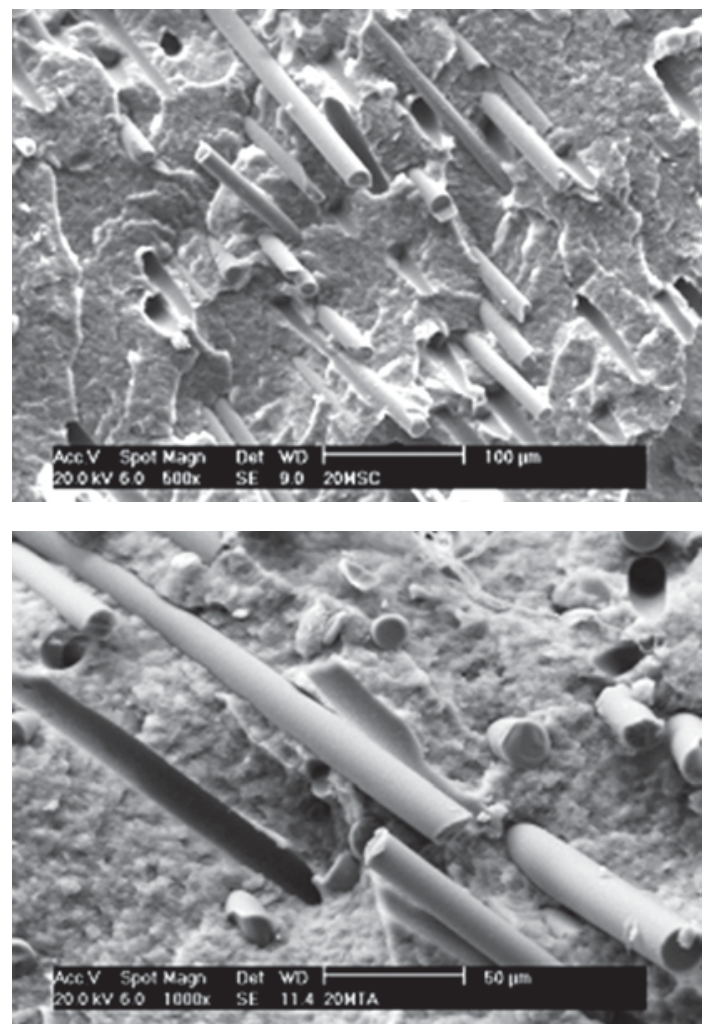

Figura 8. Micrografias eletrônicas de varredura dos compósitos com $20 \%$ de fibra moída 20MSC (em aumento de 500x) e 20MTA (em aumento de $1000 x)$.

\section{Análise segundo índice de mérito}

A partir da produtividade registrada em extrusão, calculou-se o custo de transformação e, conseqüentemente, o custo total, os quais seguem apresentados na Figura 9 (em \%, sendo o custo total do composto padrão igual a 100\%).

Observa-se que as diferenças de produtividade aproximaram os custos totais dos compósitos com 5\% de fibra de vidro, à exceção dos compósitos 5PSA e 5PSC. O menor custo da fibra picada em relação à fibra moída, ausência de dióxido de titânio e boa produtividade tornaram o custo total dos compósitos 5PSA e 5PSC menores que o do composto padrão.

A Figura 10 mostra dois índices de mérito para o carregamento nas situações de cilindro com pressão interna (condição mecânica similar à encontrada nos tubos pressurizados para água fria): Módulo elástico/massa específica e módulo elástico/massa específica/custo.

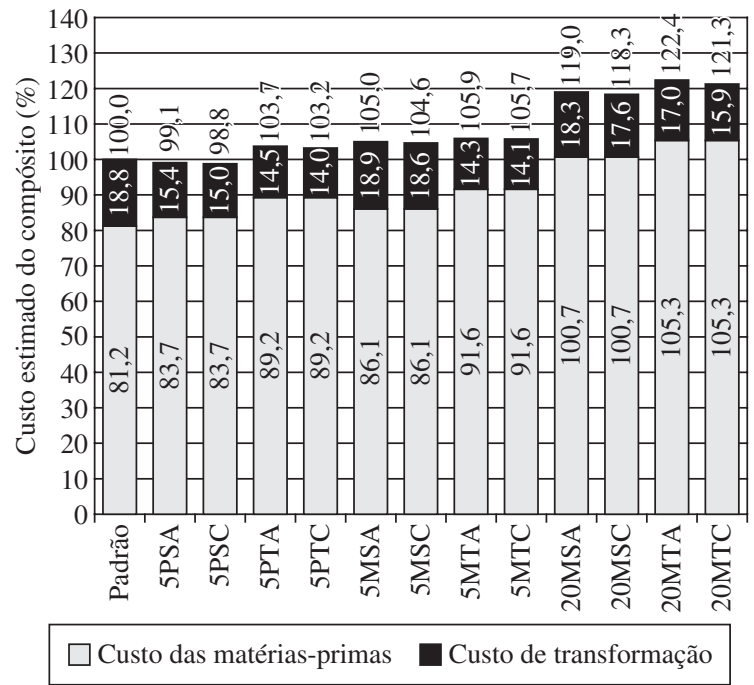

Figura 9. Custo das matérias-primas, custo de transformação e custo total dos compósitos (em \%, sendo o custo total do composto padrão igual a $100 \%)$.

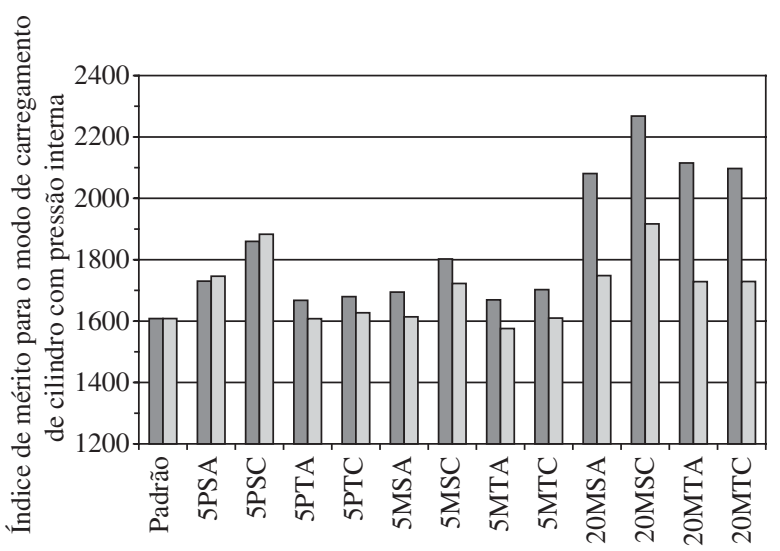

$\square$ Módulo elástico/massa específica

$\square$ Módulo elástico/massa específica/custo

Figura 10. Índice de mérito para modo de carregamento de cilindro com pressão interna. 


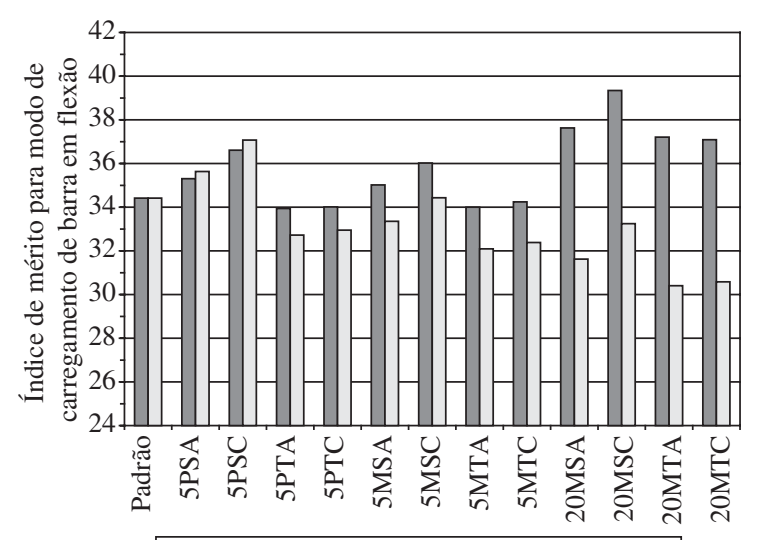

$\square$ Módulo elástico ${ }^{1 / 2} /$ massa específica $^{2}$

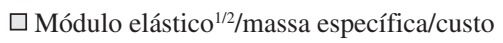

Figura 11. Índice de mérito para modo de carregamento de barra em flexão.

Nota-se que o índice de mérito módulo elástico/massa específica dos compósitos com $20 \%$ de fibra de vidro (20MSA, 20MSC, 20MTA e 20MTC) são relativamente maiores, em especial o compósito 20MSC. Mas se incluirmos o custo na análise (índice de mérito módulo elástico/massa específica/ custo), o compósito 5PSC fica muito próximo do compósito 20MSC e com valor maior que os demais compósitos com $20 \%$ de fibra de vidro. Ou seja: caso o produto a ser projetado seja um tubo de PVC que trabalhe sob pressão, os compósitos 20MSC e 5PSC produzirão tubos 19,2 e 17,1\% mais baratos que os tubos produzidos com o composto padrão, respectivamente, para o mesmo requisito mecânico (desconsiderando na análise outras propriedades da norma brasileira NBR 7665 como resistência ao impacto de dardo).

A Figura 11 mostra dois índices de mérito para o carregamento nas situações barra em flexão (condição mecânica similar à encontrada nos perfis utilizados na construção civil,

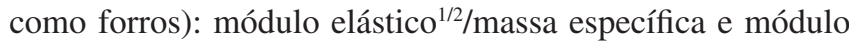
elástico ${ }^{1 / 2} / \mathrm{massa}$ específica/custo.

Observa-se que índice de mérito módulo elástico ${ }^{1 / 2} / \mathrm{massa}$ específica dos compósitos com $20 \%$ de fibra de vidro (20MSA, 20MSC, 20MTA e 20MTC) e do compósito 5PSC são relativamente maiores, em especial o compósito 20MSC. Mas se incluirmos o custo na análise (índice de mérito módulo elástico ${ }^{1 / 2}$ / massa específica/custo), apenas os compósito 5PSA e 5PSC apresentam valores acima do composto padrão. Ou seja: caso o produto em questão seja um forro de PVC que trabalhe sob flexão, os compósitos 5PSA e 5PSC produzirão forros 3,5 e 7,7\% mais baratos que os forros produzidos com o composto padrão, respectivamente, para o mesmo requisito mecânico (desconsiderando na análise outras propriedades da norma brasileira NBR 14285 como resistência ao impacto de dardo).

\section{Conclusões}

A utilização de técnicas de processamento convencionais da indústria brasileira para a incorporação de fibra de vidro em compostos de PVC rígido mostra-se inviável para compósitos com $20 \%$ de fibra picada (6,4 mm de comprimento), devido à formação de aglomerados, e viável para compósitos com até $20 \%$ de fibra de vidro moída (1,5 mm de comprimento).

A adição de fibra de vidro pouco modifica a densidade aparente do composto, o que torna os compósitos processáveis em equipamentos de extrusão convencional.

O principal ponto de atenção é a identificação de fibras de vidro com agentes de acoplagem específicos para PVC: o aumento médio de $45 \%$ no módulo de elasticidade e a grande redução na resistência ao impacto de aproximadamente $80 \%$ para os compósitos de $20 \%$ de fibra de vidro em relação ao composto padrão ocorreu devido à baixa adesão entre fibra de vidro e matriz.

Os parâmetros massa específica e custo do compósito devem ser sempre considerados no projeto de produtos: no modo de carregamento barra em flexão, o compósito 20MSC que apresentou o maior módulo de elasticidade (52\% maior em relação ao composto padrão) não se mostra interessante do ponto de vista econômico: para o mesmo requisito mecânico, um forro produzido com este compósito ficaria 3,4\% mais caro. Porém, para o modo de carregamento cilindro com pressão interna, o compósito 20MSC apresentou o melhor custo-benefício: para o mesmo requisito mecânico, um tubo produzido com este compósito ficaria 19,2\% mais barato.

\section{Referências Bibliográficas}

1. Perottoni Jr., A. - Correspondência particular ao autor (2007), baseada em números da Comissão Setorial de Resinas Termoplásticas da Associação Brasileira da Indústria Química.

2. Titow, W. V. - "PVC technology", 4. ed, W. V. Titow (ed.), Elsevier Applied Science Publisher, Londres (1984).

3. Rodolfo Jr., A., Nunes, L. R. \& Ormanji, W. - “Tecnologia do PVC", 2. ed., ProEditores Associados, São Paulo (2006).

4. Rauwendaal, C. - "Understanding extrusion", Hanser/Gardner, Cincinnati (1998).

5. White, J. L. - "Twin Screw Extrusion", Hanser Publishers, Nova York (1990).

6. Deanin, R. D.; Michaels, G. C. - Journal of Vinyl Technology, 6, p.22-24 (1984).

7. Silverman, E. M. - Plastics Compounding, p.54-57 (1986).

8. Jiang, H. et al. - Journal of Vinyl and Additive Technology, 9, p.138-145 (2003).

9. Balow, M. J.; Fuccella, D. C. - Journal of Vinyl Technology, 4, p.73-75 (1982).

10. Summers, J. W. et al. - Journal of Vinyl and Additive Technology, 12, p.99-104 (1990).

11. Polyone. - Technical Datasheets. Fiberloc ${ }^{\circledast}$ Composites. Disponível em www.polyone.com. Acesso em: 30.junho.2007.

12. Ashby, M. F. - Acta Metall, 37, p.1273-1293 (1989).

13. Ashby, M. F. - "Materials Selection in Mechanical Design", 2. ed, Butterworth-Heinemann, Oxford (1999).

14. Ferrante, M. - "Seleção de Materiais", 1. ed, EDUFSCar, São Carlos (1996). 